\title{
Regeneration of Limbal Stem Cells in the Presence of Silver and Gold Nanoparticles
}

Melinda Turani ${ }^{1}$, Gaspar Banfalvi ${ }^{1 *}$, Krisztina Kukoricza ${ }^{1}$, Judit Jakim ${ }^{1}$, Istvan Pocsi ${ }^{1}$, Adam Kemeny-Beke ${ }^{2}$ and Gabor Nagy ${ }^{1}$

${ }^{1}$ Department of Biotechnology and Microbiology, Faculty of Science, University of Debrecen, Hungary

${ }^{2}$ Department of Ophthalmology, Faculty of Medicine, University of Debrecen, Hungary

\begin{abstract}
To evaluate the potential of silver and gold nanoparticles in the healing of cornea damages cell regeneration was tested. Corneal limbal cell regrowth and structural changes in chromatin structure were studied in the presence of silver (AgNPs, $10 \mathrm{~nm}$ ) and gold nanoparticles (AuNPs, $100 \mathrm{~nm}$ ). An in vitro cell scratch model served to follow limbal cell growth by long-term scanning micro-photography. AgNPs exerted only a moderate delay on cell regeneration. Low concentration ( $80 \mathrm{ppm}$ ) of AuNPs did not affect severely, 160 and $320 \mathrm{ppm}$ extended the repopulation of limbal monolayer in a included: a) decondensed veil-like, b) fibrillary chromatin, c) supercoiled ribbon structures, d) visible chromosomes as chromatin bodies, e) early linear forms, and e) finally as metaphase chromosomes. Characteristic distortions in chromatin structures took place in nuclei in the presence of nanoparticles. Ag nanoparticles prevented the formation of linear and metaphase chromosomes. Gold particles $(80 \mathrm{ppm})$ allowed the formation of chromatin bodies, but not more condensed chromosomal forms. Higher concentrations of AuNPs prevented the formation of ribboned chromatin and higher chromosomal structures. Results show that cell regeneration and chromatin toxicity are dose dependent. In spite of their lower size, Ag nanoparticles $(10 \mathrm{~nm})$ were less toxic than larger Au particles (100 $\mathrm{nm})$.
\end{abstract}

Keywords: Time-lapse imaging; Fluorescence microscopy; Wound regeneration model; Chromatin condensation; Toxicity of nanoparticles

\section{Introduction}

Increasing amount of different types of nanoparticles has been produced since the early 1990s [1,2]. The logarithmic growth of publications related to gold nanoparticles [3] kept its momentum and reached a total of 54,243 publications by the end of 2014 . The number of silver nanoparticle publications was significantly lower corresponding to 30,748 publications [4]. The medical interest in these nanoparticles is reflected by the 15,734 gold and 7,592 silver nanoparticle publications in PubMed [5]. To avoid immunological and inflammatory reactions for tissue reconstructions, inert materials, noble metals among them silver and gold with considerable biocompatibility and availability were intended to be used to prevent corrosion and rejection of metals by tissues. Although, bulk gold is regarded bio-inert, yet at nanoscale its size (1-100 $\mathrm{nm}$ in diameter) could cause cellular effects. The shape and surface ligands should also be taken into account when the toxicity of gold nanoparticles is considered [6].

Gold nanoparticles aimed to enhance drug delivery, in vitro diagnostics, and the design of novel biometarials, bioimaging, therapy and active implantation [3]. One of the major interests in designing antineoplastic conjugated gold nanoparticles was to efficiently deliver drugs to cancer stem cells to improve the anticancer efficacy [7]. Despite the expectations of biomedical applications little is known regarding the short and long term effects of gold nanoparticles in cells. In vitro and in vivo toxicology studies of air pollution confirmed that industrially manufactured ultrafine inflammogenic nanoparticles are more toxic and generate reactive oxygen species to a greater extent than larger so called fine particles [8].

The antibacterial effect of silver known for centuries remained the most attractive property of silver that nanotechnology exploited in the textile, cosmetic industry and in the production of antiseptics. However, similarly to nanogold, the toxicity of nanosilver products remained questionable.
It was proposed that the nanoparticle screening strategy could involve physicochemical characterization, cellular and non-cellular in vitro as well as in vivo assays [9]. These strategies are consistent with the problems arising from the broad class of nanomaterials, their different sizes, shapes with modified surfaces, surface area per unit mass, shifting the nanoparticle toxicology towards in vitro tests rather than using expensive and ethically debated animal experiments [10]. It was suggested that the induction of oxidant stress by nanoparticles and the measurement of reactive species could be a reliable basis for the development of in vitro screening methodology [11].

Although, the eye, particularly the cornea is subjected to nanoparticles day by day, data regarding corneal toxicity in the presence of nanoparticles are missing. Eyedrops containing mucoadhesive nanoparticle drugs can be delivered to the surface of the eyeball for an extended period of time [12]. Before using mucoadhesive nanocomposits carrying antibiotics in the eyedops such as chloramphenicol, rifampicin (Figure 1), the components of the drug-infused nanoparticles have to be tested.

As the ophthalmological application of silver and gold nanoparticles could be considered we have tested their in vitro toxicity on human limbal stem cells of the corneal epithelium by measuring limbal cell regeneration and by following their effect on the intermediates of chromatin condensation. Limbal cell repopulation was tested using

*Corresponding author: Gaspar Banfalvi, Department of Biotechnology and Microbiology, University of Debrecen, Life Sciences Building 1.102, 1 Egyetem Sqare, Debrecen 4010, Hungary, Tel: 3652512 900; Fax: (36) 52512 925; E-mail: bgaspar@unideb.hu

Received August 13, 2015; Accepted August 26, 2015; Published August 31, 2015

Citation: Turani M, Banfalvi G, Kukoricza K, Jakim J, Pocsi I, et al. (2015) Regeneration of Limbal Stem Cells in the Presence of Silver and Gold Nanoparticles. J Environ Anal Toxicol 5: 318. doi:10.4172/2161-0525.1000318

Copyright: ( 2015 Turani M, et al. This is an open-access article distributed under the terms of the Creative Commons Attribution License, which permits unrestricted use, distribution, and reproduction in any medium, provided the original author and source are credited. 
Citation: Turani M, Banfalvi G, Kukoricza K, Jakim J, Pocsi I, et al. (2015) Regeneration of Limbal Stem Cells in the Presence of Silver and Gold Nanoparticles. J Environ Anal Toxicol 5: 318. doi:10.4172/2161-0525.1000318

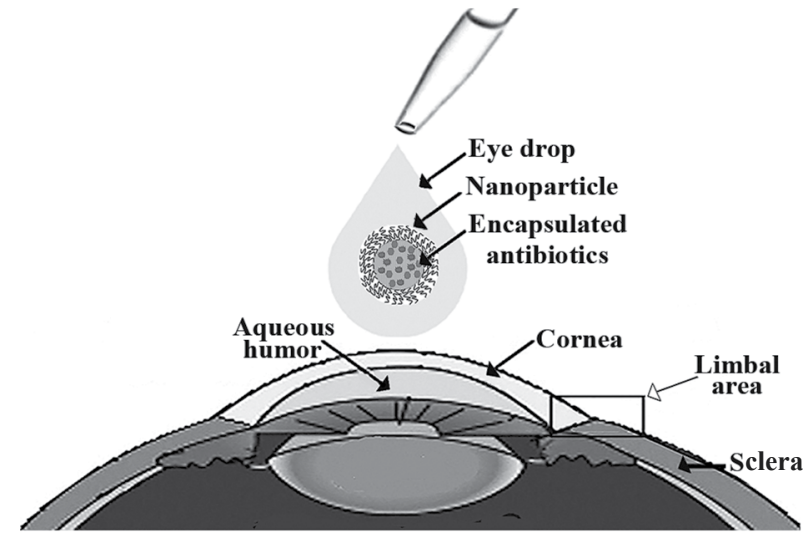

Figure 1: Schematic representation of antibiotics encapsulated nanoparticle for the treatment of cornea damages. Modified with permission [15].

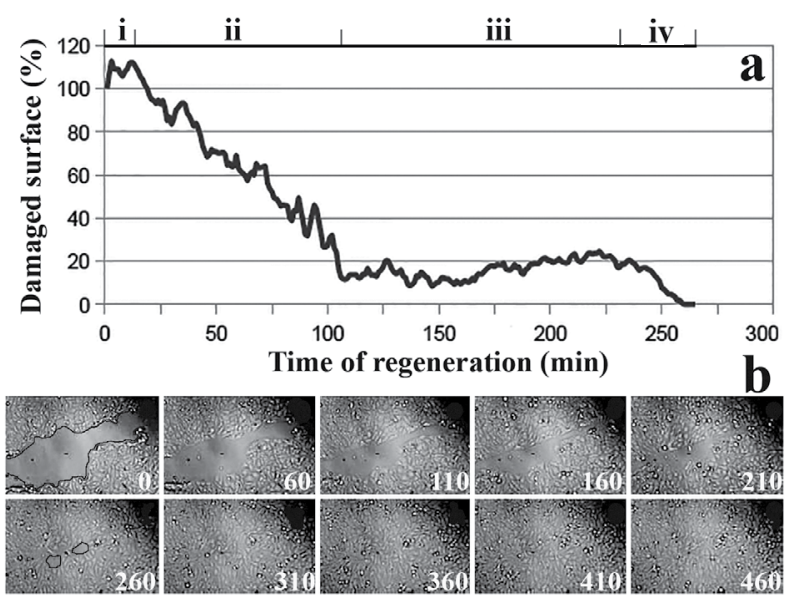

Figure 2: Regeneration of damaged surface in the absence of nanoparticles. (a) Control scratch model to mimic the regeneration of monolayer Regeneration curve plotted as a function of time. Four subphases of regeneration were distinguished (i-iv). (b) Monitoring regeneration of limbal monolayer in scratch model by long-term scanning microscopy. Limbal stem cell culture was grown until confluency of monolayer was attained $(48 \mathrm{~h}$ in glass bottom dish). The monolayer was scratched with a sterile 20 gauge hypodermic needle, resulting in $\sim 40 \%$ loss of confluency in the visual field. The empty surface caused by the scratch is indicated by the black ink from the beginning $(0 \mathrm{~min})$ of time lapse imaging to near confluency (260 min). White number at the bottom of each panel indicates the time of photography in min from the beginning of time-lapse image analysis.

an in vitro scratch model and long-term scanning microscopy. This analytical tool shows minute-by-minute the cellular changes taking place in the cell culture for an extended period of time up to three weeks. We have found that the due to their reversible effect silver nanoparticles are applicable in ophthalmology. The long regeneration time of cell cultures in the presence of nanogold particles questions the applicability of gold nanoparticles, particularly at higher concentrations and low particle size.

\section{Methods}

\section{Materials}

Gold nanoparticles (AuNPs, $100 \mathrm{~nm}$ in diameter), OD 1, stabilized suspension in citrate buffer were the products of Sigma-Aldrich Kft., Budapest, Hungary. The applied nanogold concentrations: 80, 160 and
$320 \mathrm{ppm}$ correspond to $0.41,0.81$ and $1.63 \mathrm{M}$, respectively. Nanosilver particles (AgNPs, $10 \mathrm{~nm}$ ) were obtained from Dr. Juice Pharma Kft., Miskolc, Hungary. Dilutions of the nanosilver stock solution 140, 200 and $320 \mathrm{ppm}$ correspond to $1.13,1.84$ and $2.94 \mu \mathrm{M}$, respectively. Dilutions of nanoparticles were made with Dulbecco's Modified Eagle's Medium Nutrient Mixture (DMEM-HAM'S F12) (SigmaAldrich, Budapest, Hungary) supplemented with $2 \mathrm{mM}$ L-glutamine, $23 \mathrm{mM}$ sodium bicarbonate, $10 \%$ Fetal Bovine Serum (FBS) and 1\% PSN (penicillin, streptomycin and neomycin). To eliminate bacterial contamination, PSN containing antibiotics were used as a sterilefiltered solution.

DABCO (1, 4-diazobicyclo-(2,2,2)-octane), PenicillinStreptomicin-Neomicin antibiotics (PSN-375963) were from SigmaAldrich, Budapest, Hungary. 2, 6- diamino-2-phenylindole (DAPI) was the product of Braunschweig Chemie (Braunschweig, Germany). Dextran T-150 was purchased from Pharmacia-Biochemicals (Uppsala, Sweden).

Antifade Medium consisted of $90 \%$ glycerol, $2 \%(w / w)$ DABCO, $20 \mathrm{mM}$ Tris- $\mathrm{Cl}, \mathrm{pH}$ 8.0, $0.02 \%$ sodium azide and $25 \mathrm{ng} / \mathrm{ml}$ DAPI for blue fluorescent total staining of DNA. Hypotonic Buffer for reversible permeabilization contained $9 \mathrm{mM}$ HEPES, $\mathrm{pH}$ 7.8, $5.8 \mathrm{mM}$ dithiothreitol, $4.5 \%$ dextran T-150, $1 \mathrm{mM}$ EGTA and $4.5 \mathrm{mM} \mathrm{MgCl}$. Swelling Buffer consisted of $50 \mathrm{mM} \mathrm{KCl}, 10 \mathrm{mM} \mathrm{MgSO}_{4}, 3 \mathrm{mM}$ dithiothreitol and $5 \mathrm{mM} \mathrm{NaPO}, \mathrm{pH}$ 8.0. Fixative solution contained methanol: glacial acetic acid $(3: 1)$.

\section{Long-term scanning microscopy and image analysis}

Long-term scanning (LTS) microscopy system was developed for the visualization and analysis of mammalian cell growth up to three weeks $[13,14]$. The in vitro scratch model and its combination with TLS have been described [15].

\section{Limbal scratch model mimicking corneal epithelial growth}

The scratch wound assay mimics cell behaviour during wound healing in vitro in a confluent cell layer. This model referred to as scratch model mimics the regeneration of damaged corneal epithelium faithfully by avoiding cell monolayer shrinkage and artifact formation. Detailed description of limbal stem cell isolation has been recently described [15]. Briefly, control limbal cells in glass bottom dish were grown in DMEM-F12 + 10\% FBS $+1 \%$ PSN in carbon dioxide incubator at $37^{\circ} \mathrm{C}$ at $5 \% \mathrm{CO}_{2}$ until confluency $(\sim 48 \mathrm{~h})$ was reached. The monolayer of limbal cells was scratched with the sharply cut metal tip of a sterile 20 gauge hypodermic needle. Time-lapse video microscopy combined with image analysis provided a convenient and reliable method of testing the regeneration of defect area. Limbal cells were grown in the presence of nanoparticles for the same period of time as the control population in the carbon dioxide incubator at $37^{\circ} \mathrm{C}$ at $5 \% \mathrm{CO}_{2}$ and at confluency scratched and further grown until the homogeneity of the culture was regained.

\section{Determination of silver nanoparticle size by scanning electron microscopy (SEM)}

Silver particles (AgNPs) were fixed for $30 \mathrm{~min}$ at $0^{\circ} \mathrm{C}$ with $2.5 \%$ glutaraldehyde in Phosphate Buffered Saline (PBS). After washing with PBS, particles were fixed for a further $30 \mathrm{~min}$ at $0^{\circ} \mathrm{C}$ with $2.5 \%$ osmium tetroxide in the same buffer. AgNPs were dehydrated stepwise, using increasing concentrations of ethanol in the range of $50-100 \%$, coated with gold for viewing by a Hitachi S 4300 scanning electron microscope. 
Citation: Turani M, Banfalvi G, Kukoricza K, Jakim J, Pocsi I, et al. (2015) Regeneration of Limbal Stem Cells in the Presence of Silver and Gold Nanoparticles. J Environ Anal Toxicol 5: 318. doi:10.4172/2161-0525.1000318

\section{Regeneration of damaged limbal monolayer in the presence of nanoparticles}

Seven cell cultures, including control and two types of nanoparticles of medical importance were tested by the scratch model in:

Control cells,

i) Grown in the absence of nanoparticles,

Cells grown in the presence of

ii) 140 ppm Ag nanoparticles,

iii) 200 ppm AgNPs,

iv) 320 ppm AgNPs,

v) $80 \mathrm{ppm} \mathrm{Au} \mathrm{nanoparticles,}$

vi) $160 \mathrm{ppm}$ AuNPs, and

vii) 320 ppm AuNPs.

The area of the scratch devoid of cells and the regeneration of the monolayer were followed by time-lapse microscopy until the scratched surface disappeared and confluency was restored. As the damaged areas varied from experiment to experiment, the area of defect was determined by photogmicrography using the computer-assisted ImageJ processing program of $\mathrm{NIH}$ and expressed as the percentage of residual epithelial defect at each time point.

Limbal stem cell isolation and growth mimicking corneal epithelial regereneration, reversible permeabilization of cells, isolation of nuclei, spread of nuclear structures and their fluorescence visualization have been recently described [15]

\section{Results}

\section{Regeneration of limbal monolayer}

The regeneration of damaged monolayer was followed by timelapse microscopy in a control experiment after scratching the surface of the confluent monolayer of limbal cell culture that was not subjected to nanoparticle treatment (Figure 2a). The regeneration curve of control cells was divided into four phases. (i) In the first phase lasting for about 10 min, a further $\sim 10 \%$ increase in damaged surface was observed. (ii) The second phase ( $100 \mathrm{~min})$ resulted in a steep decrease of damaged surface corresponding to the reattachment of the burst open rim of the monolayer. (iii) The third, adhesion phase represented the firm binding of cells to the underlying substrate and lasted for about 120 min. (iv) In the final phase taking $\sim 30 \mathrm{~min}$, complete confluency was attained (Figure 2a). The healing of the monolayer after scratching its surface monitored by long-term scanning microscopy showed that the regeneration of the torn apart monolayer up to complete confluency in healthy untreated cells took about $260 \mathrm{~min}$ (Figure $2 \mathrm{~b}$ ).

\section{Regeneration of limbal cell monolayer in the presence of silver nanoparticles}

The regeneration curve of the damaged monolayer after treatment with $140 \mathrm{ppm}$ AgNPs differed to some extent from that of the control population of limbal stem cells and complete regeneration was attained in about $340 \mathrm{~min}$ (Figure 3a):

(i) The first subphase ( $20 \mathrm{~min})$ showed an $18 \%$ extension of the damaged surface relative to the original $(0 \mathrm{~min})$ damage.

(ii) The reattachment phase took about $100 \mathrm{~min}$ corresponding to the attachment of control cells.

(iii) The cell adhesion phase (160 min) was steep and lasted longer than that of the control (100 $\mathrm{min})$.

(iv) The final phase to obtain complete confluency was $\sim 60 \mathrm{~min}$, longer than the control (30 min).

The size of AgNPs determined by Scanning Electron Microscopy was uniform $(9.9 \mathrm{~nm}, \mathrm{SD} \pm 1.1 \mathrm{~nm}$ ) (Figure $3 \mathrm{~b}$ ). The visualization of the healing of the scratched surface in the presence of $140 \mathrm{ppm}$ AgNPs (Figure 3c) revealed a process with a similar length of regeneration of limbal monolayer repopulation as seen in the absence of silver nanoparticles (Figure 2b).

The four subphases of regeneration of the damaged monolayer (i iv) in the presence of 340 ppm AgNPs are shown in Figure 4a.

(i) The first subphase was longer and lasted for about 350 minutes. In this phase the area of the damaged surface extended greatly, to more than twice of its original size.

(ii) The reattachment phase was only a short period ( $\sim 30 \mathrm{~min})$ seen as a steep decrease of the damaged surface that still remained $150 \%$ of the original damaged area.

(iii). The cell adhesion phase lasted for about 200 minutes, resulting in the decrease of the damaged surface to its original size.

iv). The cell culture regeneration was completed after about 1000 min (Figure 4a). The visualization of growth of individual cells by timelapse microscopy showed that the culture approached confluency after 800 min (Figure $4 b$ ).

\section{Effect of gold nanoparticles on limbal monolayer regeneration}

Gold is regarded a bio-inert metal, but the cellular toxicity of AuNPs is debated. The toxicity of nanoparticles is known to be sizedependent with small $(5-10 \mathrm{~nm})$ particles being more toxic than large $(100 \mathrm{~nm})$ ones [16]. We have used the less toxic, large $100 \mathrm{~nm}$ AuNPs at increasing concentrations $(80,200$ and $320 \mathrm{ppm})$ to see the dose dependent toxicity and to decide whether larger gold nanoparticles or smaller silver nanoparticles $(5 \mathrm{~nm})$ are more toxic.

\section{Regeneration of monolayer after 80 ppm AuNP treatment}

The dose-dependent effect of AuNPs on in vitro regeneration of monolayers of limbal cells is seen as regeneration curves in Figure 5a-5c. At low (80 ppm) AuNP concentration the regeneration time was not longer than that of the control population $(260 \mathrm{~min})$. In the first subphase the empty area of the scratched monolayer showed an additional increase from $100 \%$ to $130 \%$. The slope of the regeneration profile in the presence of $80 \mathrm{ppm}$ AuNPs (Figure 5a) was similar to the treatment with $140 \mathrm{ppm}$ silver nanoparticles (Figure 3a).

\section{Regeneration of limbal monolayer after 200 ppm AuNP treatment}

The panel of (Figure 5b) shows that the initial damaged area of the limbal monolayer increased to about $140 \%$. The the reattachment period taking $\sim 100 \mathrm{~min}$, the slope of the regeneration curve was extended particularly in the adhesion and final phases to $900 \mathrm{~min}$.

Regeneration of limbal monolayer treated with $320 \mathrm{ppm}$ AuNPs

In the initial subphase the damaged surface increased from $100 \%$ to $220 \%$ indicating that in presence of AuNPs the monolayer suffered a 

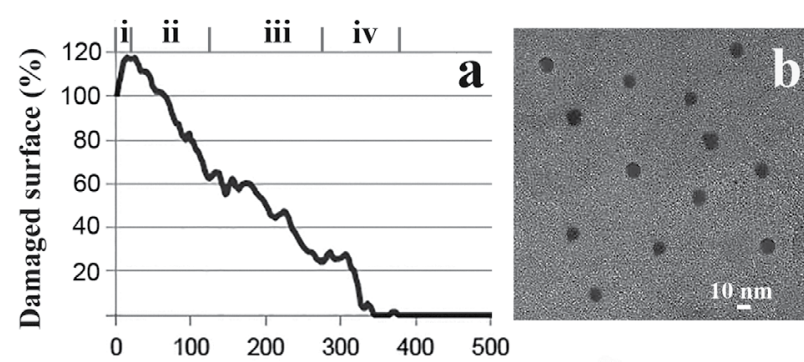

Time of regeneration $(\mathrm{min})$
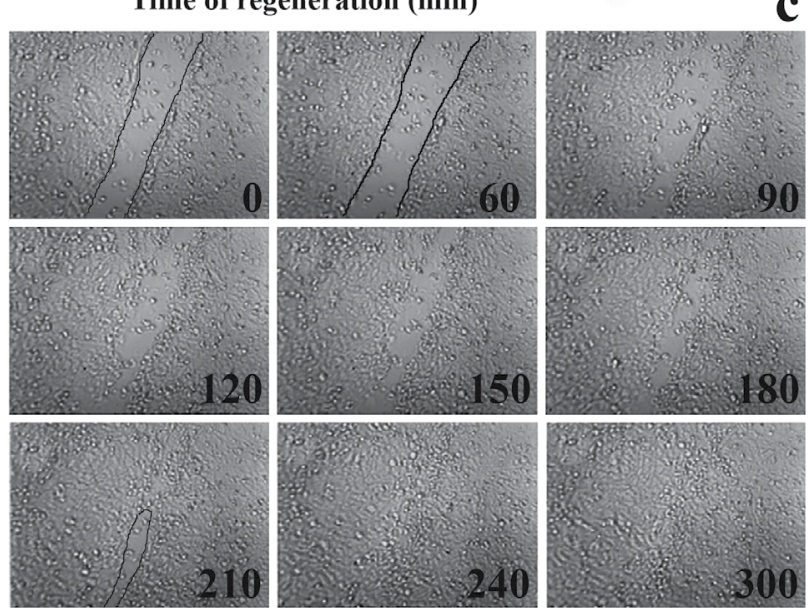

Figure 3: Regeneration of damaged limbal cell monolayer in the presence of $140 \mathrm{ppm}$ silver nanoparticle concentration. Limbal cells were grown in the presence of Ag nanoparticles to $100 \%$ confluency. (a) Repopulation of empty area plotted as a regeneration curve. Four subphases of regeneration were distinguished (i-iv) as in Figure 2a. (b) Scanning electron microscopy images of $10 \mathrm{~nm}$ silver nanoparticles. (c) Monitoring limbal stem cell regrowth in the presence of $140 \mathrm{ppm}$ Ag nanoparticles in glass bottom dish. After reaching confluency the surface of the monolayer was scratched with a sterile 20 gauge needle and regeneration traced until the disrupted area was healed. Black numbers indicate the time of photography in minutes from the beginning of time-lapse image analysis.

severe detachment (Figure $5 c$, phase i). In the reattachment period (100 $\mathrm{min}$ ) the damaged surface was reduced by only $\sim 20 \%$ (Figure $5 \mathrm{c}$, phase ii), with the adhesion period and final regeneration extended to 1200 min (Figure $5 c$, phases iii and iv).

The regeneration of the damaged monolayer in the presence of 80 ppm AuNPs to complete restoration lasted for 260 min (Figure 5d). The restoration of the integrity of the monolayer after $320 \mathrm{ppm}$ AuNP treatment is seen in Figure 5e. Upto 480 min the empty belt devoid of cells was wider than the area of the original scratch at the beginning of the regeneration process. Complete regeneration was attained after $\sim 1000 \mathrm{~min}$. The lack of dead cells throughout the regeneration process pointed to reversible damages of nanogold particles.

\section{Chromatin condensation in control limbal cells}

Intermediates of chromatin condensation in healthy, untreated limbal stem cells [15] were similar to those seen in other mammalian (CHO, Indian muntjac, murine preB, and human erythroleukemia) cells [17] and included highly decondensed round chromatin veil in early $\mathrm{S}$ phase (Figure 6a-6d), polarized chromatin veil (Figure 6e-6h), supercoiled chromatin ribbon (Figure 6i-6p), condensed chromatin subdivided to five chromatin clusters (Figure 6q), ribbons turning to chromatin bodies, corresponding to the earliest visible forms of chromosomes (Figure 6r-6t), early elongated forms of linear chromosomes (Figure 6u-6w) and metaphase chromosomes (Figure $6 \mathrm{x}$ ). These forms correspond to common intermediates of chromatin condensation seen earlier in other healthy cells and are shown only to compare them with damages caused by AgNPs and AuNPs.

\section{Chromatin changes induced by AgNPsL}

(Figure 7) shows retracted chromatin condensation caused by Ag nanoparticles in limbal cell cultures. The growth of limbal cells in the presence of $140 \mathrm{ppm}$ AgNPs for $24 \mathrm{~h}$ did not cause drastic distortions in chromatin structures in the early stages of condensation (Figure 7A/1-4). Round chromatin veil was seen rarely, but polarized and distorted (Figure 7B/1-4). Lagging elongation of chromatin veil could be explained by the reduced activity of chromatin supercoling (Figure 7C/1-4). Due to the inefficiency of supercoiling the formation of early visible forms of chromosomes was not only delayed, but the chromatin remained trapped in prematurely condensed long, thin ribbons (Figure 7D/1-4 and 7E/1-4). Inefficient coiling of thin ribbons resulted in smaller than regular chromatin bodies with considerable part of chromatin veil remaining decondensed (Figure 7F/1-3). The most condensed structures occasionally reached the stage of chromatin bodies (Figure $7 \mathrm{~F} / 4$ ), but not the stages of elongated or metaphase chromosomes.

High (320 ppm) AgNP concentration did not cause drastic changes in chromatin condensation relative to lower (140 ppm) AgNP concentration (Figure 7, right panels). Chromatin structures were smaller than the average, but the absence of apoptotic bodies excluded the posssibility of apoptotic cell death. Beside the nuclear shrinkage, early phases of chromatin condensation could be characterized by the rejection of decondensed chromatin veil around the nucleus (Figure 7A/5-8), and by its expulsion as a comet-like tail (Figure 7B/5-8). The opening of nuclei (Figure 7C/5-8) allowed the formation of semicircular, decondensed chromatin forms (Figure 7D/5-8), and chromatin ribbons (Figure 7E/5-8). These structures were condensed occasionally to higher order folding of chromatin bodies (Figure 7F/5$8)$.

\section{Chromatin changes induced by AuNPs}

The treatment of limbal cells at lower (80 ppm) nanogold concentration caused similar changes in chromatin structures as silver nanoparticles at $160 \mathrm{ppm}$ concentration (left panels in Figure 8). Nuclei containing chromatin veil were distorted (Figure 8A/1-4). Polarization of chromatin veil (Figure 8B/1-4 and $8 \mathrm{C} / 1-4$ ) and uncoiled ribbons (Figure 8D/1-4) dominated the pictures. Occasionally condensed nuclei with comet-like long decondensed tails were seen (Figure 8E/12). Long chromatin ribbons (Figure 8E/3-4) could turn to chromatin bodies (Figure 8F/1-3), but early elongated prechromosomes (Figure $8 \mathrm{~F} / 4$ ) were rarely seen and metaphase chromosomes were absent.

High concentration (320 ppm) of AuNPs prevented supercoiling, manifested in the presence of unregular thin chromatin ribbons, the formation of chromatin bodies was prevented, early elongated and metaphase chromosomes were missing (right panels of Figure 8).

\section{Discussion}

Silver nanoparticle size $(5,20$ and $50 \mathrm{~nm})$ is known to affect cytotoxicity with smaller nanoparticles causing higher cellular toxicity and 4-9\% apoptosis in A549, SGC-7901, HepG2 and MCF-7 cells [18]. Similar examination of size-dependent cellular toxicity of AgNPs confirmed that smaller sized AgNPs $(10 \mathrm{~nm})$ had a greater ability to 
Citation: Turani M, Banfalvi G, Kukoricza K, Jakim J, Pocsi I, et al. (2015) Regeneration of Limbal Stem Cells in the Presence of Silver and Gold Nanoparticles. J Environ Anal Toxicol 5: 318. doi:10.4172/2161-0525.1000318
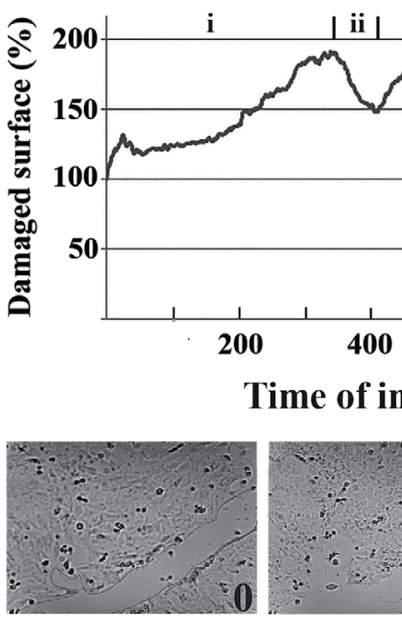

iii

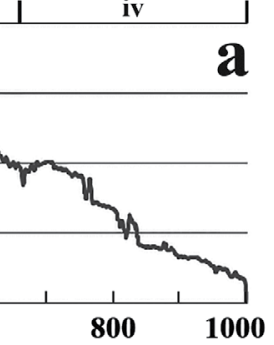

Time of incubation (min)
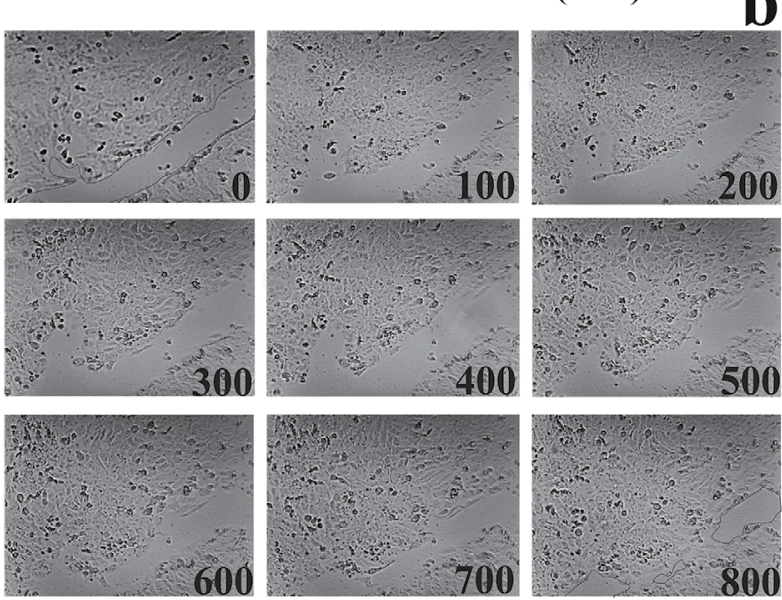

Figure 4: Regeneration of damaged limbal cell monolayer in the presence of $320 \mathrm{ppm}$ concentration of silver nanoparticles. Limbal cells were grown in the presence Ag nanoparticles to confluency. (a) Repopulation plotted as a regeneration curve. Four subphases of regeneration were distinguished (i-iv) as in Figure 2a). (b) Monitoring limbal stem cell regrowth in the presence of $320 \mathrm{ppm} \mathrm{Ag}$ nanoparticles in glass bottom dish. After reaching confluency the surface of the monolayer was scratched with a sterile 20 gauge needle and regeneration traced. Black numbers indicate the time of photography in minutes from the beginning of time-lapse image analysis.

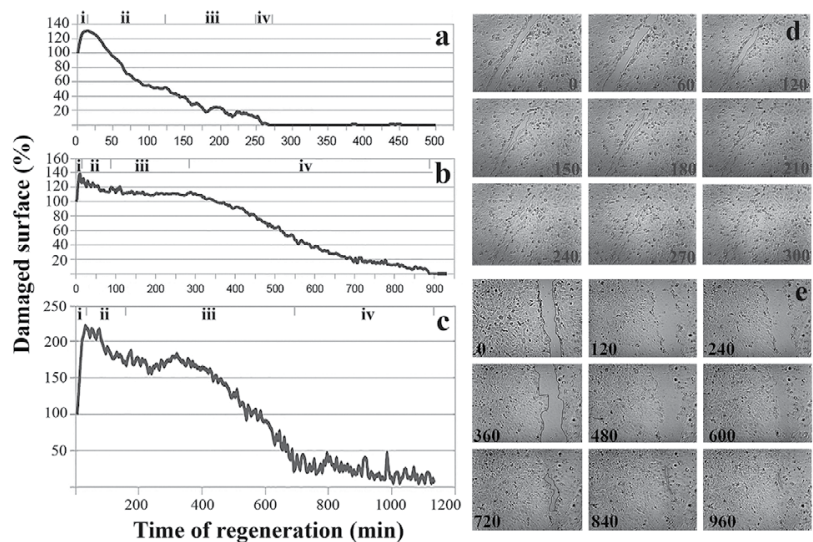

Figure 5: Regeneration of damaged limbal cell monolayer in the presence of gold nanoparticles. Cells were grown in the presence of 80,160 or $320 \mathrm{ppm}$ Au nanoparticles. After attaining confluency the surface of the monolayer was scratched and regeneration traced by time-lapse imaging until the disrupted area was healed. Regeneration curves after: (a) $80 \mathrm{ppm}$ Au nanoparticle, (b) 200 ppm Au nanoparticle, and (c) 320 ppm Au nanoparticle treatments. Monitoring limbal stem cell regrowth: (d) in the presence of $80 \mathrm{ppm} \mathrm{Au}$ nanoparticles and (e) in the presence of $320 \mathrm{ppm}$ Au nanoparticles. Black numbers indicate the time of photography in minutes from the beginning of time-lapse image analysis.
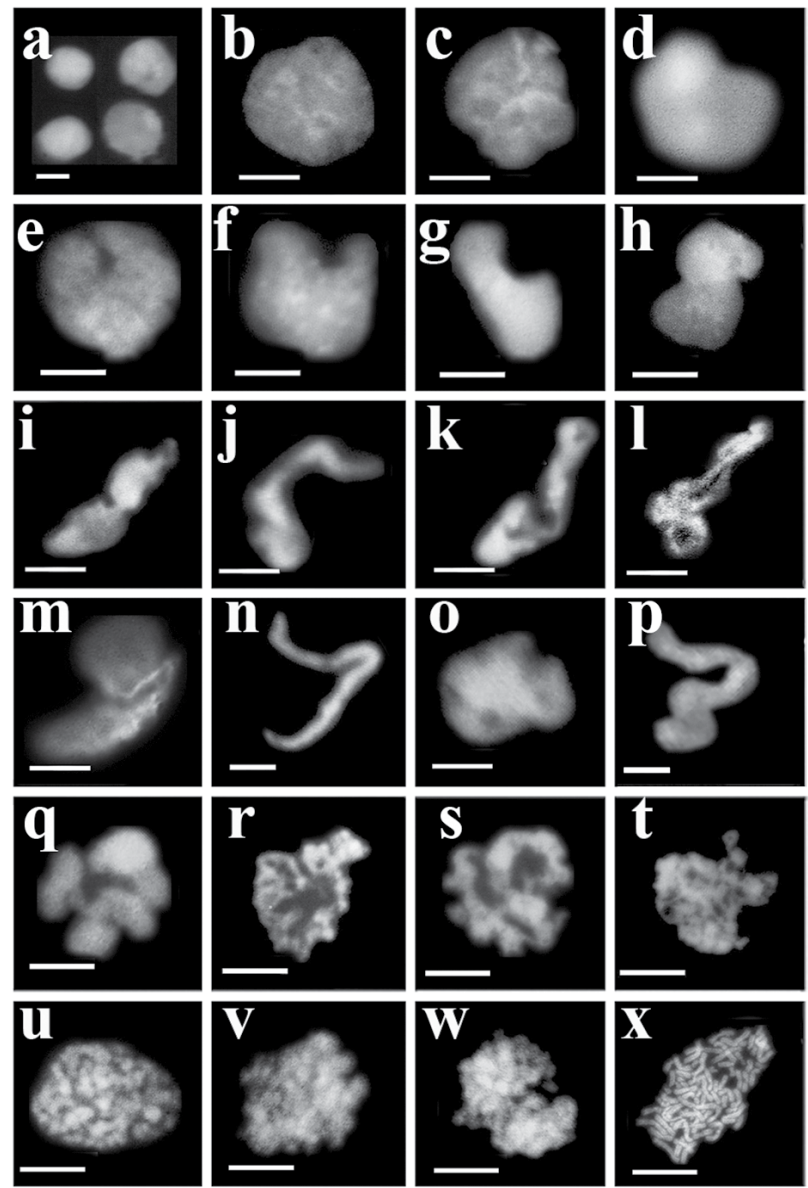

Figure 6: Intermediates of chromatin condensation in control cells. Limbal cells were grown in T-25 flask in the absence of nanoparticles for $24 \mathrm{~h}$, harvested, reversibly permeabilized and subjected to chromatin isolation and visualization as described in the Methodology. Transitory changes of chromosome condensation: chromatin veil (a-d), polarized veil (e-h), chromatin ribbon (i-q), chromatin bodies (early forms of visible chromosomes) $(r-t)$, elongated forms $(u-w)$ and metaphase chromosomes $(x)$. Bars, $5 \mu \mathrm{m}$ each.

induce apoptosis in MC3T3-E1 and PC12 cells than the larger sized AgNPs (50 and $100 \mathrm{~nm}$ ) [16].

Recent studies doubted the safety of nano-sized gold particles [19], due to their electrical, chemical, mechanical, thermal and optical properties [1,19-21]. Indeed, gold nanoparticles unlike the bioinert bulk gold, are able to enter cells and exert adverse effects by interacting with membranes and smaller subcellular compartments, while unable to enter the nucleus [22-26]. Most of the studied gold nanoparticles had dimensions less than $100 \mathrm{~nm}$ and entered cells via receptor mediated endocytosis [22,24,27]. Conflicting reports indicate that gold nanoparticles can be both nontoxic and toxic. Consequently in vitro results remained inconclusive regarding the toxicity of nanogold [28]. In spite of the fact that available data vary widely in their methods and conclusions [29], most of the nanotoxicological data come from in vitro studies.

Before antibiotics could be used in nanocomposits toxicity data of chloramphenicol and rifampicin were collected. We have compared antibiotic-induced cytotoxic effects and tested the regeneration of human limbal stem cells [15]. In the recent study the toxicity of two 
Citation: Turani M, Banfalvi G, Kukoricza K, Jakim J, Pocsi I, et al. (2015) Regeneration of Limbal Stem Cells in the Presence of Silver and Gold Nanoparticles. J Environ Anal Toxicol 5: 318. doi:10.4172/2161-0525.1000318
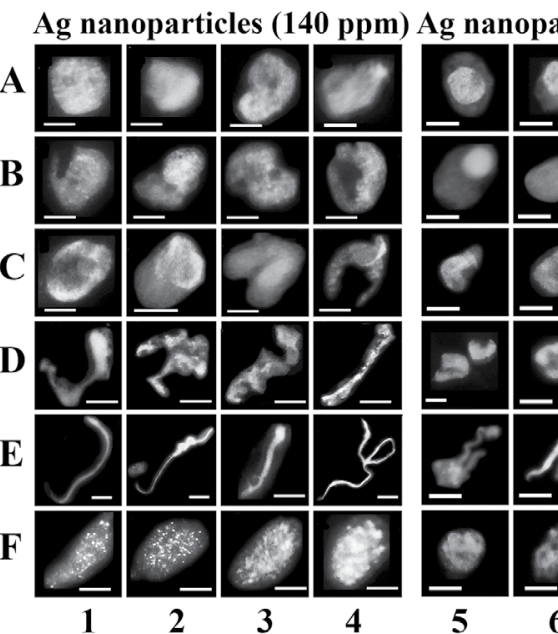

clinically relevant nanoparticles were tested: small silver nanoparticles $(10 \mathrm{~nm})$, are able to diffuse into cells, and larger $(100 \mathrm{~nm})$, gold nanoparticles, which are unable to enter cells. In spite of expectations the regeneration of limbal cells in the presence of small silver nanoparticles was faster, than in the presence of larger gold nanoparticles.

Intermediates of chromatin condensation of healthy limbal cells resembled closely other mammalian tumor cells visualized earlier [17]. Beside the delayed regeneration of the damaged limbal cell monolayer, genotoxicity specific chromatin modifications were induced by nanoparticles. In the presence of silver nanoparticles chromatin condensation can be characterized by the rejection of decondensed chromatin veil around the nucleus, expulsion as a comet-like tail, lack of elongated and metaphase chromosomes and absence of apoptotic bodies. We have tested earlier the susceptibility of chromatin toward silver nitrate in human K562 erythroleukemia and human keratinocyte $\mathrm{HaCaT}$ cells. Changes in large-scale chromatin structures in the concentration range of $0.5-5 \mu \mathrm{M}$ silver nitrate revealed that $\mathrm{K} 562$ cells were more susceptible to silver nitrate than $\mathrm{HaCaT}$ cells. Elevated silver nitrate concentrations $(10-15 \mu \mathrm{M})$ caused nuclear shrinking with infrequent formation of apoptotic bodies. Typical nuclear changes induced by $\mathrm{Ag}^{+}$ions involved the extrusion of decondensed chromatin seen as chromatin tail (comet) formation, that could be accounted for by the reduced activity of supercoiling [29]. The comparison of ionic and nanosilver indicates that $\mathrm{Ag}^{+}$ions and nanosilver particles exert similar characteristic chromatin changes with little and negligible cell death.

In the presence of low AuNP concentration the reduced supercoiling activity could turn chromatin ribbons to chromatin bodies, but as elongated prechromosomes were only occasionally seen, metaphase chromosomes could not be formed. The concentration dependent inhibition of chromatin condensation became evident at higher AuNP concentrations, affecting early chromatin condensation, with regular chromatin ribbons being absent. Inhibition of early chromatin folding prevented the formation of higher chromosomal structures including chromatin bodies, elongated prechromosomes and metaphase chromosomes.

In spite of the delayed regeneration of limbal monolayer in the presence of silver nanoparticles, and prevention of final stages of chromatin condensation neither apoptotic nor necrotic cells were seen in the regenerating cell culture. We assume that small $(10 \mathrm{~nm})$ silver nanoparticles exert only cytostatic but no cytocidic effects. Similar observations were made with the slightly toxic gold nanoparticles, at least at low concentration preventing the formation of compact structures at the final stage of chromosome condensation. To the opposite, higher concentration of AuNPs blocked chromatin ribbon formation indicating that gold nanoparticles interfere with chromatin supercoiling that is essential for chromosome condensation.

\section{Conclusion}

Treatment of limbal cells with silver and gold nanoparticles caused the delayed regeneration of the stem cell monolayer and prevented the completion of the chromosome condensation process. The moderate delay in regeneration time relative to control cells was similar when small $(10 \mathrm{~nm})$ silver or large $(100 \mathrm{~nm})$ gold nanoparticles were used. The lack of apoptotic cells in the presence of both types of nanoparticles indicated that the inhibition could be reversible. The idea of reversibility is in conformity with the observation of others that upon exposure of sublethal concentrations of AgNPs for long times, cells remained viable and their growth retarded. Similarly, 
Citation: Turani M, Banfalvi G, Kukoricza K, Jakim J, Pocsi I, et al. (2015) Regeneration of Limbal Stem Cells in the Presence of Silver and Gold Nanoparticles. J Environ Anal Toxicol 5: 318. doi:10.4172/2161-0525.1000318

genotoxicity was found to be reversible upon removal of AgNPs from cell culture [30], suggesting that chromatin changes are not permanent. However, extended regeneration time associated with the treatment of higher concentrations (160, $320 \mathrm{ppm})$ of large AuNP particles could raise concern about smaller $(<100 \mathrm{~nm})$ nanogold particles that could be toxic alone or in combination with experimental drugs. As neither ionic silver, nor silver nanoparticles, nor nanogold particles generated apoptotic bodies, the cellular changes tested are likely to be reversible. By placing imaging of chromatin deformities in a broader perspective, changes in interphase chromatin structure are regarded early markes and sensitive indicators of chromosome abnormalities before metaphase chromosomes would be formed. Observations regarding the low toxicity of antibiotics (rifampicin and chloramphenicol [15] and the reversible effect of AgNPs could establish the safe use of silver nanocomposites in ophthalmology. The design of silver nanocomposites carrying antibiotics is under way. The slower regeneration in the presence of gold nanoparticles poses some concern, thus their ophthalmological use is not considered.

\section{Acknowledgements}

This work was sponsored by TAMOP 4.2.4. A/2-11-1-2012-0001 grant to GN and TAMOP-4.2.2/B-10/1-2010-0024 grant to AK-B. The authors have no other relevant affiliations or financial involvement with any organization or entity with a financial interest in or financial conflict with the subject matter or materials discussed in the manuscript apart from those disclosed. The last two authors contributed equally to this study. GB has written the manuscript. No other writing assistance was utilized in the production of this manuscript.

\section{Appendix and Supplementary data}

Supporting videos associated with this article can be found in the online version at http://dx.doi.org/ as Video 1 for Figure 2b, Video 2 for Figure 3c, Video 3 for Figure $4 \mathrm{~b}$, Video 4 for Figure $5 \mathrm{a}$, Video 5 for Figure $5 \mathrm{~d}$ and Video 6 for Figure $5 e$.

\section{References}

1. Aillon KL, Xie Y, El-Gendy N, Berkland CJ, Forrest ML (2009) Effects of nanomaterial physiochemical properties on in vivo toxicity. Adv Drug Deliver Rev 6: 457-466.

2. Tervonen T, Linkov I, Figueira JR, Steevens J, Chappell M, et al. (2012) Riskbased classification system of nanomaterials. J Nanopart Res 11: 757-766.

3. Jain S, Hirst DG, O'Sullivan JM (2012) Gold nanoparticles as novel agents for cancer therapy. Br J Radio 85: 101-113.

4. Web of knowledge. www.webofknowledge.com

5. PubMed. http://www.ncbi.nlm

6. Yah CS (2013) The toxicity of gold nanoparticles in relation to their physiochemical properties. Biomed Res 24: 400-413.

7. Sun TM, Wang YC, Wang F, Du JZ, Mao CQ, et al. (2014) Cancer stem cell therapy using doxorubicin conjugated to gold nanoparticles via hydrazone bonds. Biomaterials 35: 836-845.

8. Stone $\mathrm{V}$, Johnston $\mathrm{H}$, Clift $\mathrm{MJ}$ (2007) Air pollution, ultrafine and nanoparticle toxicology: cellular and molecular interactions. IEEE Trans Nanobioscience 6: 331-340.

9. Oberdörster G, Maynard A, Donaldson K, Castranova V, Fitzpatrick J, et al (2005) Principles for characterizing the potential human health effects from exposure to nanomaterials: elements of a screening strategy. Part Fibre Toxicol 2: 8 .

10. Donaldson K, Borm PJ, Castranova V, Gulumian M (2009) The limits of testing particle-mediated oxidative stress in vitro in predicting diverse pathologies; relevance for testing of nanoparticles. Part Fibre Toxicol 6: 13.

11. Nel A, Xia T, Mädler L, Li N (2006) Toxic potential of materials at the nanolevel. Science 311: 622-627.

12. Liu Y, Zhu J, Zhu YH, Yang XZ, Wang J, et al. (2014) Cancer stem cell therapy using doxorubicin conjugated to gold nanoparticles via hydrazone bonds. Biomaterials 35: 836-845.
13. Banfalvi G, Sarvari A, Nagy G (2012) Chromatin changes induced by Pb and $\mathrm{Cd}$ in human cells. Toxicol in Vitro 26: 1064-1071.

14. Nagy G, Hennig GW, Petrenyi K, Kovacs L, Pocsi I, et al. (2014) Time-lapse video microscopy and image analysis of adherence and growth patterns of Candida albicans strains. Appl Microbiol Biotechnol 98: 5185-5194.

15. Turani M, Banfalvi G, Peter A, Kukoricza K, Kiraly G, et al. (2015) Antibiotics delay in vitro human stem cell regrowth. Toxicol In vitro 29: 370-379.

16. Kim TH, Kim M, Park HS, Shin US, Gong MS (2012) Size-dependent cellular toxicity of silver nanoparticles. J Biomed Mater Res A 100: 1033-1043.

17. Banfalvi G, Nagy G, Gacsi M, Roszer T, Basnakian AG (2006) Common pathway of chromosome condensation in mammalian cells. DNA Cell Biol 25: 295-301.

18. Liu W, Wu Y, Wang C, Li HC, Wang T, et al. (2010) Impact of silver nanoparticles on human cells: effect of particle size. Nanotoxicology 4: 319-330.

19. Jenkins T, Halaney DL, Sokolov KV, Ma LL, Shipley HJ, et al. (2013) Excretion and toxicity of gold-iron nanoparticles. Nanomedicine: Nanotech Biol Med 9 : 356-365.

20. Jennings T, Strouse G (2007) Past, present, and future of gold nanoparticles. Bio-Applications of Nanoparticles Springer, New York.

21. Brouard D, Viger ML, Bracamonte AG, Boudreau D (2011) Label-free biosensing based on multilayer fluorescent nanocomposites and a cationic polymeric transducer. Acs Nano 5: 1888-1896.

22. Shukla R, Bansal, V, Chaudhary M, Basu A, Bhonde RR, et al. (2005) Biocompatibility of gold nanoparticles and their endocytotic fate inside the cellular compartment: a microscopic overview. Langmuir 21: 10644-10654.

23. Pernodet N, Fang X, Sun Y, Bakhtina A, Ramakrishnan A, et al. (2006) adverse effects of citrate/gold nanoparticles on human dermal fibroblasts. Small 2: 766 773

24. Chithrani BD, Chan WC (2007) Elucidating the mechanism of cellular uptake and removal of protein-coated gold nanoparticles of different sizes and shapes. Nano Letts 7: 1542-1550.

25. Khan JA, Pillai B, Das TK, Singh Y, Maiti S (2007) Molecular effects of uptake of gold nanoparticles in HeLa cells. Chembiochem 8: 1237-1240.

26. Alkilany AM, Nagaria PK, Hexel CR, Shaw TJ, Murphy CJ, et al. (2009) Cellular uptake and cytotoxicity of gold nanorods: molecular origin of cytotoxicity and surface effects. Small 5: 701-708.

27. Nativo P, Prior IA, Brust M (2008) Uptake and intracellular fate of surfacemodified gold nanoparticles. ACS Nano 2: 1639-1644.

28. Ostrowski AD, Martin T, Conti J, Hurt I, Harthorn BH (2009) Nanotoxicology: characterizing the scientific literature, 2000-2007. J Nanopart Res 11: 251257.

29. Nagy G, Turani M, Kovacs KE, Banfalvi G (2011) Chromatin changes upon silver nitrate treatment in human keratinocyte $\mathrm{HaCaT}$ and K562 erythroleukemia cells: Cellular effects of heavy metals. Springer, Dordrecht.

30. Castiglioni S, Caspani C, Cazzaniga A, Maier JA (2014) Short-and long-term effects of silver nanoparticles on human microvascular endothelial cells. World J Biol Chem 5: 457-464. 